\title{
Dos Décadas de Cambios en el Escenario Político y Partidario de Bolivia: el lugar del MAS y de los demás
}

\author{
Rosiene Freitas \\ Universidade Federal de Minas Gerais \\ Natália Guimarães Duarte Sátyro \\ Universidade Federal de Minas Gerais
}

\section{Introducción}

El objetivo de este artículo es describir los principales cambios en los sistemas político y partidario de Bolivia en su historia reciente, con énfasis en el análisis del lugar y papel del MAS (Movimiento al Socialismo) en esa trayectoria. No hay un intento de explicar un fenómeno, como en los estudios deductivos, sino hacer un mapeo de los cambios en la institucionalidad política y partidaria de Bolivia en las dos últimas décadas, hecho a partir de un rastreo de los procesos que conforman el cambio de ese escenario institucional. Este trabajo se justifica por la incipiente literatura sobre Bolivia y por la necesidad de profundizar el caso boliviano entre los estudios sobre la izquierda latinoamericana. La idea es entender los procesos recientes en el escenario político de Bolivia mapeando tanto sus actores institucionales y las reglas del juego, cuanto los cambios por los cuales pasaron el tablero y las piezas del juego. Se trata, además, de un trabajo descriptivo hecho a la luz del neoinstitucionalismo histórico, que coloca las instituciones en el centro del proceso decisorio, dado que sus características estructurantes determinan los resultados que son producidos. Considerando la entrada del MAS en el escenario político boliviano y su consolidación como actor político central, en contrapunto a la desestructuración de los partidos tradicionales, se vuelve mandatorio un mapeo sistemático de los procesos recientes en la historia política boliviana.

Primero discutimos cómo surgió el MAS y cómo él se convirtió en un actor central dentro de la arena política en las dos últimas décadas. En seguida, habiendo un partido de izquierda como el MAS alcanzado el gobierno central, analizamos los escenarios político y partidario en el cual él gobierna. En un próximo paso, analizamos la relación del MAS con los diversos actores, o sea, con el parlamento, la oposición y los movimientos sociales - y, de otro lado, con los Departamentos y municipios, a través de la cuestión de la autonomía departamental. Los resultados señalan el desmantelamiento de los partidos tradicionales - pero un sistema partidario volátil -, el rediseño de las reglas del juego, y la consolidación del MAS como una fuerza política capaz de presentar un nuevo proyecto.

\section{EI MAS como alternativa a la izquierda en Bolivia}

El MAS es considerado como un ejemplo de movimiento de izquierda que emergió de movimientos sociales rurales y se expandió para incluir una gama más amplia de estos movimientos. Fue creado 
en 1994 en el I Congreso sobre Tierra, Territorio e Instrumento Político como Asamblea por la Soberanía de los Pueblos (ASP). En ese Congreso participaron sindicatos de campesinos, parte de la COB (Central Obrera Boliviana, fundada en 1952) y de otras asociaciones indígenas y de trabajadores urbanos; CSUTB (Confederación Única de Trabajadores Campesinos de Bolivia, creada en 1979); FNMCB-BS (Federación Nacional de Mujeres Campesinas de Bolivia Bartolina Sisa, creada en 1980); y CIDOB (Central Indígena de los Pueblos del Oriente Boliviano, creada en 1982, ahora llamada Confederación de Pueblos Indígenas de Bolivia). También participaron ONGs vinculadas a la iglesia católica y el CEJIS (Centro de Estudios Jurídicos y Pesquisa Social) ${ }^{1}$, de donde vinieron varios futuros ministros de Evo Morales (Reis, 2013, p. 70). En 1997, debido a discordancias entre liderazgos del partido, Evo Morales fundó el Instrumento Político por la Soberanía de los Pueblos (IPSB), poco después acrecentando el nombre "Movimiento al Socialismo" (MAS).

Aunque haya asumido un formato institucional, de modo a tomar parte en las instituciones democráticas liberales de representación, el MAS tiene una propuesta de transcender la definición clásica de partido. De ahí su autodefinición como instrumento político de los movimientos indígenas y campesinos. O sea, es una extensión política de un conjunto de organizaciones sociales que dirigieron su formación como un movimiento táctico, en el cual la participación en procesos electorales puede implicar en su representación en las instituciones democráticas liberales. Ese concepto cuestiona las formas partidarias clásicas, al mismo tiempo en que favorece un compromiso directo de las organizaciones sociales en el campo político. Como instrumento político, el MAS propone una participación tanto institucional cuanto el protesto en las calles. Esa duplicidad quiere significar el establecimiento de relaciones y continuidades entre los dos espacios, desafiando el tradicional límite entre la acción contestataria y la acción partidaria. Para el MAS, el acceso a los niveles de decisión del Estado debe darse por los propios movimientos sociales, y no por el empoderamiento de los movimientos políticos a través del acceso a esos niveles (Anria, 2010; Zegada, 2012). O sea, a pesar de que él agregue diferentes actores sociales y políticos, difiere del concepto de partido catch-all, por ejemplo, en la medida en que no está completamente concentrado en el escenario electoral, substituyendo espacios de debates ideológicos más profundizados por un éxito electoral inmediato o abdicando del papel de la militancia en el partido.

En la explicación del origen del MAS, y de su ascensión, están los resultados de los ajustes económicos y de las reformas sociales de los gobiernos neoliberales entre 1985 y 2005, que no mejoraron las condiciones de vida de la población; la lucha contra la erradicación del cultivo de hoja de coca en el Chapare (región de Cochabamba); la promulgación de la Ley de Participación Popular en 1994 y de la Ley de Descentralización Administrativa en 1995; la reforma del artículo 60 de la Constitución de 1967 ocurrida en 1994, introduciendo la elección de diputados uninominales, con importantes efectos de empoderamiento para el sindicalismo campesino e indígena; y la crisis del Estado y de las instituciones de representación en Bolivia (Mayorga, F. 2008; Anria, 2010; Madrid, 2011). De forma general esos acontecimientos proporcionaron la entrada en la escena política de nuevos actores del movimiento social organizado.

\footnotetext{
${ }^{1}$ ONG creada en 1978 que actúa en el campo de los derechos humanos en una perspectiva jurídico-social, acompañando sectores vulnerables de la sociedad en la defensa de sus derechos individuales y colectivos. Disponible en: http://cejis.org/. Acceso en: 03 dic. 2018.
} 
La Ley de Participación Popular y la Ley de Descentralización Administrativa permitieron la creación de cerca de 300 municipios e instituyeron elecciones directas municipales, desencadenando un proceso de "ruralización de la política" (Zuazo, 2008 apud Anria, 2010, p. 106). Las organizaciones indígenas y campesinas empezaron a participar con representantes en las elecciones locales, alcanzando gradualmente el nivel nacional. Además, los movimientos sociales ganaron visibilidad al nivel nacional a partir de las protestas iniciadas en enero de 2000 en Cochabamba, cuando exigieron el fin de la concesión y la no privatización de la Empresa de Agua del Tunari, administradora de ese recurso natural, que lo vendía a altos precios a la población ${ }^{2}$. El aumento de la insatisfacción social a partir de 2000 reflejó una crisis del Estado y desnudó los límites de la gobernanza neoliberal. Ese contexto afectó la legitimidad de los partidos políticos tradicionales en tanto que instituciones de representación, y facilitó la incorporación de nuevas formaciones políticas. El MAS, que desde el inicio de su fundación se puso en contraposición al sistema tradicional, fue estratégicamente ampliando su campo de acción, incorporando intelectuales en su estructura y ganando los sectores medios urbanos.

En 2003 las protestas se volcaron contra la intención del gobierno Sánchez de Lozada (20022003) de exportar el gas natural boliviano a los EUA y a México a través de Chile, a bajos precios, mientras grandes segmentos de la población no eran abastecidos ${ }^{3}$. Las movilizaciones fueron fuertemente reprimidas por el gobierno, con decenas de muertes, lo que contribuyó para intensificar los conflictos y las luchas contra las políticas implementadas. En medio a las presiones, el presidente Sánchez de Lozada renunció, en octubre de 2003. Carlos Mesa, su sucesor, renunció en 2005. Ese contexto de instabilidad llevó a la anticipación de elecciones presidenciales para ese mismo año, 2005, cuando el MAS venció con 54\% de los votos (Zegada, 2010; Weyland, 2009; Anria, 2010).

Las diferencias del MAS respecto a los otros partidos bolivianos se refieren a la presencia de nuevos actores y reglas en los procesos democráticos. La consulta popular es un ejemplo, que tiene como uno de los objetivos mantener una relación orgánica entre el partido y las organizaciones. Para eso, el MAS coordina una variedad de actores sociales y políticos aglutinados bajo el liderazgo de Evo Morales. Internamente, se constata una ascensión linear desde las organizaciones hasta el partido propiamente, lo que implica que el compromiso político sea el mismo en los espacios del partido y de los sindicatos y movimientos. La legitimación de los líderes se basa fundamentalmente en sus trayectorias en las organizaciones y en la participación en la movilización por demandas concretas. Sin embargo, el MAS también se construye a partir de otras fuentes con liderazgos cuya participación, menos orgánica, puede ser incorporada por invitación. Esa necesidad de abrirse a otros espacios, en los cuales las relaciones no son mediadas por el corporativismo, remite a la complexidad del MAS constituirse como un instrumento político. Considerando las tradicionales reglas de ascensión a los cargos y los procesos democráticos en el MAS, la entrada de actores en el partido por otros mecanismos, al establecer una relación de subordinación a los dirigentes que poseen una trayectoria organizativa, es uno elemento de complejidad en su organización y funcionamiento (Mayorga, F. 2008).

Existe en el MAS un hibrido de formas democráticas, algunas heredadas de tradiciones

\footnotetext{
${ }^{2}$ Las protestas quedaron conocidos como la Guerra del Agua.

${ }^{3}$ Guerra del Gas.
} 
sindicales o comunitarias, otras de la democracia liberal. Un ejemplo fue el énfasis a las formas de representación como el diputado uninominal, observada en la propuesta para la Asamblea Constituyente instalada en 2006, así como también la defensa de los "usos y costumbres" como formas de mediación y tomada de decisión. La figura del diputado uninominal es considerada una forma de representación próxima a las comunidades; ya la institución de la elección de representantes de los pueblos indígenas de acuerdo con los usos y costumbres refleja la coexistencia de formas comunitarias de elección y de voto universal. Se trata del reconocimiento formal de otras instituciones políticas, sean ancestrales o producidas en los procesos organizativos más recientes.

En el interior del partido, a su vez, las relaciones están altamente definidas por la presencia del liderazgo de Evo Morales, que influencia de forma directa en la complexidad funcional y organizativa del MAS en tanto presidente del país, jefe del partido y dirigente máximo de las seis federaciones de cultivadores de hoja de coca del Chapare. Como líder, fue gradualmente consolidando su control sobre el partido, hecho posible debido a su popularidad y la frágil institucionalización del MAS caracterizada por la ausencia de reglas y de una burocracia en los moldes de los partidos tradicionales -, y una propuesta de los liderazgos de no transformarlo en un partido convencional y de tratarlo como un instrumento político (Madrid, 2011).

Sin embargo, hay que destacar algunas críticas que caracterizan el proyecto del MAS y el líder Evo Morales como populistas. Sin embargo, la identificación de un partido como populista normalmente está asociada a la ausencia de un partido efectivo y a una movilización vertical de masas populares con poca o ninguna autonomía (Reis, 2013). El MAS no se encuadra en eso. Las organizaciones sociales en Bolivia tienen grande densidad organizativa, capacidad de movilización e incidencia política, y eso aumentó con el reciente fortalecimiento de los movimientos campesino e indígena, principales bases de apoyo del partido. La naturaleza del liderazgo de Evo Morales, a su vez, debe ser analizada en el contexto del instrumento político MAS: se vale de diferentes formas de mediación y establece identificaciones con la población que le permiten amplia legitimidad, aunque no una capacidad desmedida de maniobra (Mayorga, F. 2012).

\section{Cuando los partidos tradicionales se fragilizan y la izquierda entra en la escena política}

Teniendo en cuenta las peculiaridades del MAS en tanto partido político y movimiento que se vale de los espacios institucionales formales e informales para la construcción política, nos interesa posicionarlo en el sistema político y partidario boliviano. Asumimos que el sistema partidario tiene reflejos en la formación de los gobiernos y en la forma por la cual los actores dentro de la arena política manejan las demandas, y siendo así tiene importancia en la forma como los gobiernos ejercen el poder y en su capacidad de formular e implementar políticas. En el sistema político, el presupuesto de la acción de los partidos guarda relación con el nivel de institucionalización del sistema partidario (Mainwaring y Scully, 1995; Mainwaring y Torcal, 2005; Pribble, 2013).

Entre 1980 y 2002 ningún candidato obtuvo mayoría absoluta de los votos en las elecciones generales en Bolivia, y un segundo turno congresual fue el proceso de definición de la presidencia y de la vicepresidencia en Bolivia (Torrico, 2014). Hasta 1994 la segunda vuelta - en el cual participarían los diputados y senadores electos -, se produjo entre los tres candidatos más votados. La alteración de ese sistema fijó el segundo turno congresual entre los dos candidatos más votados y los legisladores electos pasaron a votar en la chapa de cada partido - con los candidatos a la 
presidencia y los respectivos vices - en dos turnos: uno para la elección del presidente y otro para la elección del vicepresidente.

Según la literatura, ese procedimiento aproximó el presidencialismo boliviano a un régimen de tipo parlamentar, en el cual el líder de gobierno es electo por el Poder Legislativo. A su vez, la permanencia en los cargos del presidente y del vice no dependía de la preservación de la confianza del Congreso, rasgo ese típico de un régimen presidencialista en el cual ambos los poderes tienen mandatos fijos e independientes respecto al apoyo de uno al otro. La confluencia de eses aspectos caracterizó el sistema político boliviano como un "presidencialismo parlamentarizado" (Mayorga, R. 2004; Torrico, 2014; Nunes, 2015). Esa característica del sistema político boliviano tenía, aún, dos elementos característicos. Primero, al adoptar listas cerradas, el sistema delegaba mayores poderes al Legislativo. Segundo, la posibilidad de que los partidos menores aumenten su poder en la formación de coaliciones en la segunda vuelta, constituía un incentivo para que ellos presenten candidatos, favoreciendo el multipartidismo.

Así, Bolivia transitó entre 13 partidos en 1980; 18 en 1985; 14 en 1993; y 11 en 2002. En las elecciones presidenciales de 2005 existían 8 partidos actuantes (Nunes, 2015). Considerando que el sistema electoral de lista cerrada con voto único y la alta fragmentación electoral y partidaria imposibilitaban la formación de mayoría legislativa por parte de una sola fuerza, el presidencialismo parlamentarizado en Bolivia estuvo basado en la lógica de coaliciones interpartidarias.

Es necesario resaltar, primero, que el gobierno post dictadura de la Unidad Democrática y Popular (UDP) 4 entre 1982-1985 no logró crear bases políticas sólidas para el enfrentamiento de los problemas políticos y socioeconómicos de la transición a la democracia y eso culminó con una hiperinflación y con su pérdida de legitimidad. En este escenario, hubo la necesidad de un acuerdo entre los principales partidos, como importante paso para garantizar el sistema democrático (Mayorga, R. 1994, p. 36), que consistió en la modificación de los patrones tradicionales de hacer política y en la construcción de consensos básicos en torno de la democracia y de la necesidad de desarrollar una política económica de mercado.

En 1985 el MNR ${ }^{5}$, con Paz Estenssoro, asumió la presidencia en el segundo turno congresual (Cuadro 1). El partido fue electo con el apoyo del $\mathrm{MIR}^{6}$ y de la $\mathrm{ADN}^{7}$. El plan económico llevado por el gobierno fue apoyado por medio del Pacto por la Democracia firmado entre el MNR y la ADN, principal partido de oposición. Por el acuerdo, la ADN se comprometía también a apoyar en el Congreso las iniciativas del Ejecutivo para combatir la crisis económica. El Pacto por la Democracia fue respectado hasta febrero de 1989, cuando el MNR rompió unilateralmente el acuerdo para viabilizar la candidatura de Sánchez de Lozada, o sea, sin tener de disputarla con un candidato de la ADN.

\footnotetext{
${ }^{4}$ Alianza de izquierda firmada en 1977 entre MNR-I, MIR, PRIN y PCB.

${ }^{5}$ Movimiento Nacional Revolucionario, fundado en 1942 el (MNR), en una posición de centroizquierda, con base en las clases medias regionales y en los sectores nacionalistas del ejército.

${ }^{6}$ Movimiento de Izquierda Revolucionaria, fundado en 1971, agrupando intelectuales marxistas, sectores independientes y la democracia cristiana.

${ }^{7}$ Acción Democrática Nacionalista, partido de derecha fundado en 1979 por Hugo Banzer. Posteriormente incluyó el PIR y una facción de la FSB. Desde 2006 tuvo poca participación política, pero aún está oficialmente inscrito.
} 
Cuadro 1 - Partidos y coaliciones gobernantes en Bolivia entre 1985 y 2015

\begin{tabular}{|c|c|c|c|c|c|c|c|c|}
\hline Mandatos & $\begin{array}{c}1985- \\
1989 \\
\end{array}$ & $\begin{array}{l}1989- \\
1993\end{array}$ & $\begin{array}{c}1993- \\
1997 \\
\end{array}$ & $\begin{array}{l}1997- \\
2002 \\
\end{array}$ & $\begin{array}{l}2003- \\
2005\end{array}$ & $\begin{array}{l}2006- \\
2010\end{array}$ & $\begin{array}{l}2010- \\
2015\end{array}$ & $\begin{array}{l}2015- \\
2020\end{array}$ \\
\hline $\begin{array}{l}\text { Partido do } \\
\text { Presidente }\end{array}$ & MNR & MIR & MNR & ADN & MNR & MAS & MAS & MAS \\
\hline $\begin{array}{l}\text { Partidos da } \\
\text { coalizão }\end{array}$ & $\mathrm{ADN}$ & $\mathrm{ADN}$ & UCS & $\begin{array}{l}\text { MIR, UCS, } \\
\text { CONDEPA, } \\
\text { NFR }\end{array}$ & $\begin{array}{l}\text { MIR, UCS, } \\
\text { NFR }\end{array}$ & & & \\
\hline Presidente & $\begin{array}{l}\text { Paz } \\
\text { Estenssoro }\end{array}$ & $\begin{array}{l}\text { Paz } \\
\text { Zamora }\end{array}$ & $\begin{array}{l}\text { Sánchez } \\
\text { de } \\
\text { Lozada }\end{array}$ & $\begin{array}{l}\text { Hugo } \\
\text { Bánzer }\end{array}$ & Lozada/Mesa & $\begin{array}{l}\text { Evo } \\
\text { Morales }\end{array}$ & $\begin{array}{l}\text { Evo } \\
\text { Morales }\end{array}$ & $\begin{array}{l}\text { Evo } \\
\text { Morales }\end{array}$ \\
\hline
\end{tabular}

Fuente: Adaptado de Nunes (2015).

En las elecciones de 1989 el escenario de fragmentación política se repitió y, casi por inercia, la designación del presidente ocurrió también en el ámbito del Congreso, eligiendo Jaime Paz Zamora - líder del MIR y tercero candidato más votado en el primer turno - para el mandato presidencial de 1989-1993. Paz Zamora, antiguo adversario político, fue apoyado por la ADN (Cuadro 1). El acuerdo post electoral entre MIR y ADN (Acuerdo Patriótico) permitió un diálogo entre esas importantes fuerzas políticas del país.

En 1993 el MNR alcanzó una importante votación en las elecciones (35,55\% de los votos). Esa victoria, con el apoyo Unión Cívica Solidaridad (UCS) ${ }^{8}$, condujo Sánchez de Lozada a la presidencia para el período 1993-1997. Con la alianza del MRTKL ${ }^{9}$ con el MNR, por la primera vez Bolivia tuvo un vicepresidente de origen indígena: Víctor Hugo Cárdenas. En esa gestión 1994 se introdujeron las primeras reformas en la Constitución de 1967. Al crear circunscripciones uninominales e incorporar el procedimiento de mayoría simple, estas reformas afectaran la forma de elección de mitad de los miembros de la Cámara de Diputados, permitiendo la descentralización de funciones administrativas para los gobiernos departamentales y municipales y la ampliación de la participación popular en el sistema político (Carraffa, 2007).

Las circunscripciones uni y plurinominales fueron utilizadas por la primera vez en 1997, en las elecciones para los poderes Ejecutivo y Legislativo. En el Ejecutivo la alianza entre MIR, CONDEPA $^{10}$, UCS, NFR ${ }^{11}$ y ADN dio la victoria de Hugo Banzer (ADN) en las elecciones presidenciales de este mismo año, en la misma lógica de los pactos anteriores.

En 2002 Evo Morales obtuvo 20,9\% de los votos en las elecciones presidenciales, lo mismo que Manfred Reyes Villa del NFR (Nueva Fuerza Republicana) ${ }^{12}$. Sánchez de Lozada (MNR), el más votado, obtuvo $22,5 \%$ de los votos válidos y fue electo presidente en el segundo turno congresual en una alianza con el MIR, UCS y NFR (Carraffa, 2007). En que pese la posible fuerza de la alianza,

\footnotetext{
${ }^{8}$ Partido de centroderecha fundado en 1989.

${ }^{9}$ Movimiento Revolucionario Túpac Katari de Liberación, fundado en 1985.

${ }^{10}$ Partido de cuño populista fundado en 1988. Fue el primer grande partido en abrazar la identidad cultural indígena de los aimaras. Fue deshabilitado en 2002.

${ }^{11}$ Nueva Fuerza Republicana, partido de centroderecha fundado en 1995 por Manfred Reyes Villa después de dejar la ADN.

${ }^{12}$ Partido de centroderecha fundado en 1995 por Manfred Reyes Villa después de dejar la ADN (Acción Democrática Nacional), partido de derecha creado por el dictador Hugo Banzer en 1979.
} 
MNR y MIR - partidos relevantes en los gobiernos desde 1985 -, asumieron el poder con una coalición ya debilitada con relación al Pacto por la Democracia de 1985 entre MNR y ADN (52,8\% de los asientos en 2002 versus 75\% en 1985) y al Acuerdo Patriótico de 1989 entre MIR y ADN (60\% de las sillas parlamentares). El MAS, sin embargo, se destacó como la principal fuerza contra el status quo, tanto en las calles como en el Congreso, donde consiguió elegir 27 deputados y 8 senadores (20,94\% de los votos) (Mayorga, R. 2004).

El impulso a la territorialización del voto, bien como los nuevos espacios de competencia política en los ámbitos local y municipal creados a partir de la aplicación de la Ley de Participación Popular y de la Ley de Descentralización Administrativa, provocaron cambios en las elecciones de 2002. Amplios sectores campesinos e indígenas participaron votando por opciones propias como el MAS y el MIP ${ }^{13}$, fortaleciendo una representación político-partidaria basada en la identidad étnicocultural ${ }^{14}$. La aplicación del nuevo sistema electoral para la elección de diputados en distritos uninominales fortaleció la representatividad del sistema político y permitió la renovación de 70\% de la Cámara, aunque haya tenido efectos en el nivel de profesionalismo de los parlamentares, reduciéndolo (Mayorga, R. 2004).

Para los tres principales partidos en el escenario político desde la redemocratización - ADN, MNR e MIR - las elecciones de 2002 significaron una caída de difícil recuperación (Gráficos 1-6). Entre sus efectos destacamos la reconfiguración de los partidos relevantes para la arena política, la fuerte polarización entre los partidos tradicionales y las nuevas fuerzas políticas, el avance cualitativo de la representación política - en el sentido del aumento de su diversidad -, y una importante redistribución territorial del voto. Los nuevos movimientos campesinos se habían transformado en movimientos políticos y alcanzaron una representación de carácter histórico. Además de la expresividad del MAS en esas elecciones, el MIP alcanzó 6,09\% de los votos y seis sillas en el parlamento (Carraffa, 2007).

\footnotetext{
${ }^{13}$ Movimiento Indígena Pachakuti, partido de izquierda fundado en 2000 por indígenas aimaras del altiplano boliviano.

${ }^{14}$ Cabe señalar que aunque el MIP tiene la identidad étnico-cultural en su esencia, así como el MAS, el partido fue fundado con el objetivo de reconstruir los dominios incas bajo las reglas monoetnicas aymaras y, al excluir no solo a los blancos y mestizos, pero también en los pueblos quechua y guaraní, el sufrió un impacto electoral en 2002, obteniendo solo el 6\% de los votos, mientras que el MAS siguió su propuesta de expandir la participación de los grupos blancos, mestizos e indígenas, y expandir las alianzas con los grupos a la izquierda (Maíz, 2009, p. 23-24).
} 
Gráfico 1 - Proporción de votos en las elecciones presidenciales en Bolivia en 1993, por partido

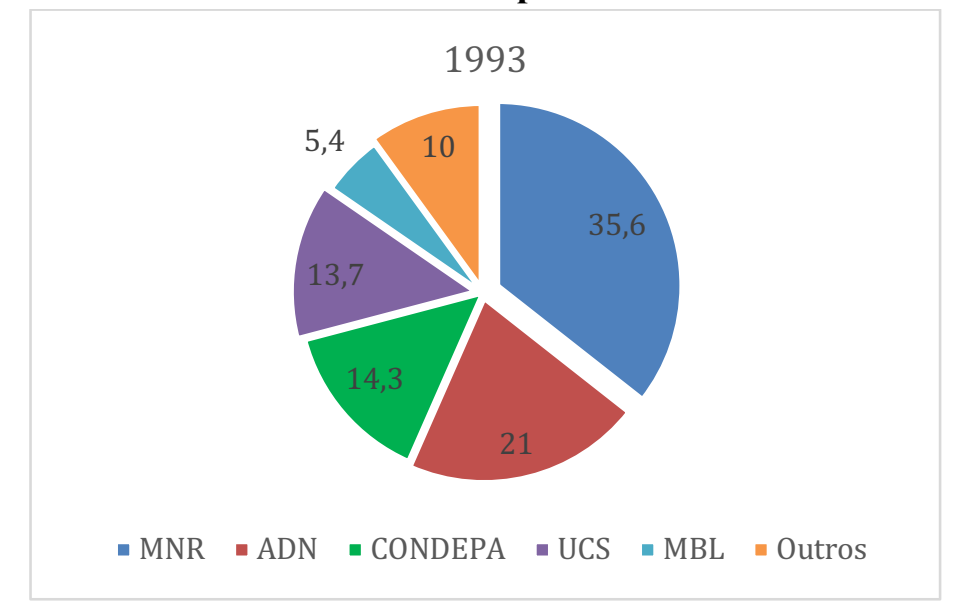

Fuente: Adaptado de Mendieta (2010).

Gráfico 2 - Proporción de votos en las elecciones presidenciales en Bolivia en 1997, por partido

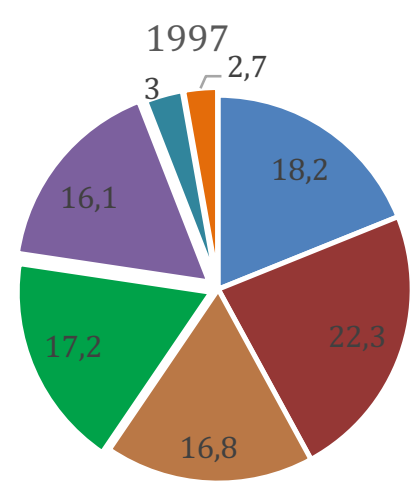

- MNR - ADN - MIR - CONDEPA - UCS - MBL - Outros

Fuente: Adaptado de Mendieta (2010).

Gráfico 3 - Proporción de votos en las elecciones presidenciales en Bolivia en 2002, por partido 2002

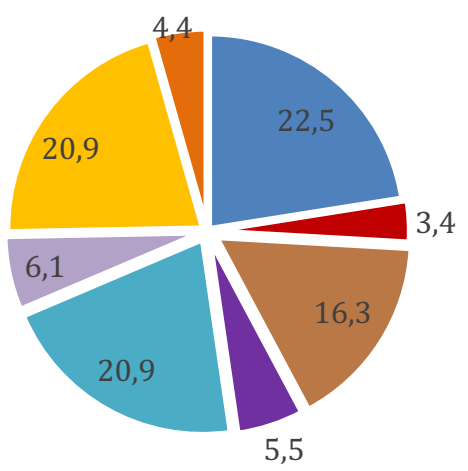

- MNR - ADN - MIR - UCS - NFR - MIP - MAS - Outros

Fuente: Adaptado de Mendieta (2010). 
Gráfico 4 - Proporción de votos en las elecciones presidenciales en Bolivia en 2005, por partido

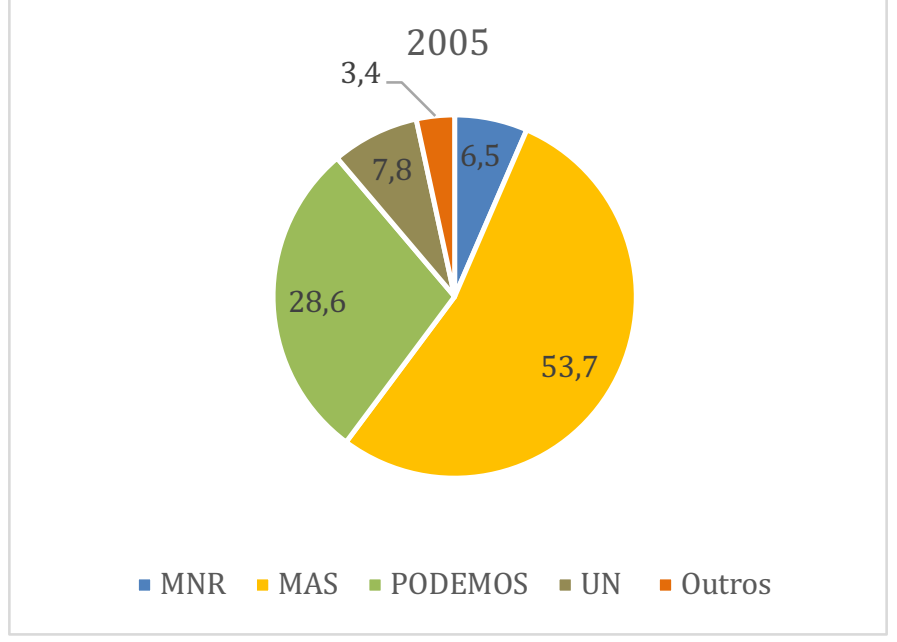

Fuente: Adaptado de Mendieta (2010).

Gráfico 5 - Proporción de votos en las elecciones presidenciales en Bolivia en 2009, por partido

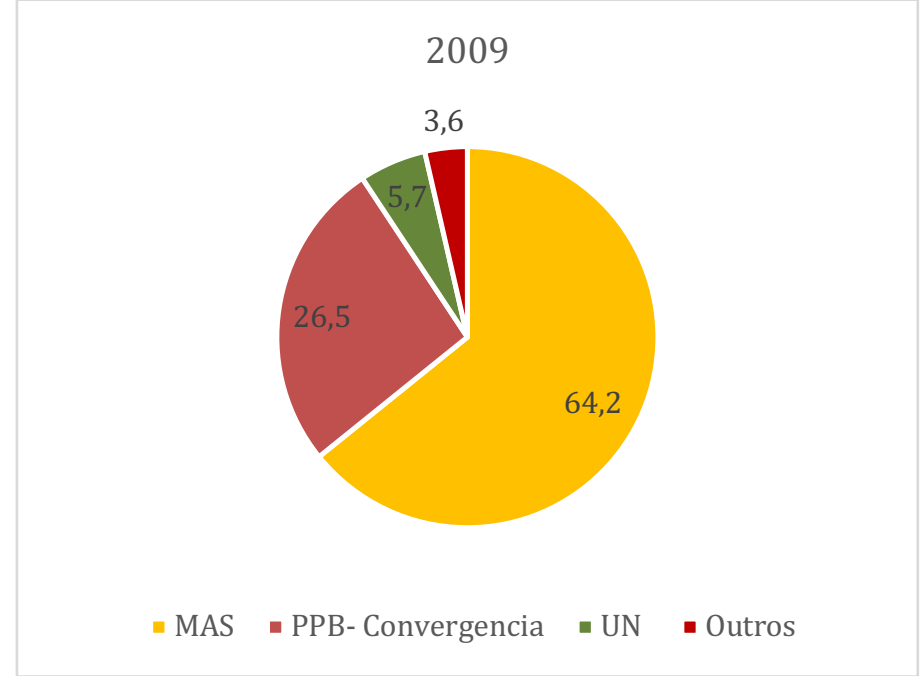

Fuente: Adaptado de Mendieta (2010).

Gráfico 6 - Proporción de votos en las elecciones presidenciales en Bolivia en 2014, por partido

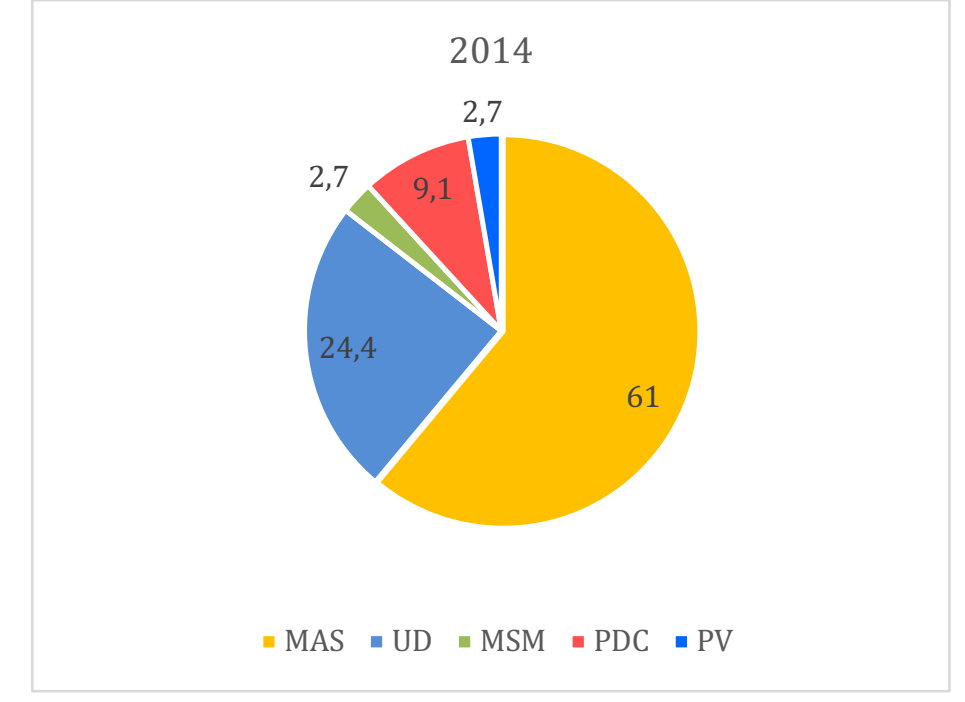

Fuente: Adaptado de Mendieta (2010). 
Se observa aquí el anuncio de un cambio institucionalizado, el encerramiento de un ciclo. Hasta ese momento el periodo democrático boliviano había sido dominado por los partidos tradicionales, con base en un pacto que reunía diferentes actores políticos, inicialmente unidos básicamente contra la dictadura, pero que fueron se desvelando a la derecha del espectro ideológico. Varios factores contribuyeron para el debilitamiento de los partidos tradicionales. Con el surgimiento de movimientos políticos de tendencia contestataria - en cierta medida el neo-populista NFR en 1995, el MAS en 1997 y el MIP en 2000 -, se abrió una nueva distancia ideológica con relación a los partidos tradicionales. Esos partidos nuevos absorbieron el descontentamiento con la situación de pobreza y exclusión social y con los desaciertos del gobierno de Hugo Banzer (1997-2002) y juntos tuvieron cerca de mitad de los votos (Gráficos 1-6). La polarización revelada por propuestas de cambios que, de un lado, defendían el desmonte radical y la reconstrucción del Estado y, de otro, las reformas moderadas, fue también un efecto del resurgimiento de tensiones étnico-culturales latentes desde la transición para la democracia. El discurso contestatario al neoliberalismo y a la Democracia Pactada debilitó la tendencia anteriormente observada en torno de los partidos tradicionales y la polarización en el sistema partidario alimentó la crisis política en 2003 y 2005, resultando en la renuncia de dos presidentes en el mismo mandato y en la convocación de nuevas elecciones.

Otro factor llamativo en el cambio en el sistema de partidos boliviano fue la aprobación en 2004 de la Ley de Agrupaciones Ciudadanas y Pueblos Indígenas, que permitió la organización de partidos a escala municipal, regional o departamental a través de la filiación a la circunscripción deseada. En 2004, se reconocieron alrededor de 400 grupos de ciudadanos y pueblos indígenas, la mayoría de ellos con el objetivo de competir en un solo municipio. En 2010, aproximadamente la mitad de estas organizaciones compitieron, incluyendo partidos, agrupaciones ciudadanas y pueblos indígenas (Ballivián, 2016). A pesar de esta adaptación a la apertura que trajo la ley, los partidos tradicionales perdieron cuadros y desmantelaron sus estructuras territoriales. Anteriormente, un candidato necesitaba pertenecer a un partido, y los partidos querían establecer sus bases territoriales, tanto para mejorar sus resultados electorales como para reclutar a los futuros candidatos. La nueva ley ha hecho superfluos a los partidos políticos y muchos no han conseguido mantener sus sedes y cuadros (Ballivián, 2016, p. 315), pero muchos de sus líderes se organizaron bajo el nuevo formato dado por la ley ${ }^{15}$. Sin embargo, Ballivián (2016, p. 316) evalúa que si bien la Ley de Agrupaciones Ciudadanas y Pueblos Indígenas ha afectado el sistema de partidos, al menos a nivel local, su ruptura se asocia sobre todo a la crisis derivada del abrupto final del gobierno de Sanchéz de Lozada (MNR).

Por fin, el cambio en el escenario institucional también se da por el hecho de que en 2005 el MAS obtuvo la mayoría de los votos en el primer turno y se convirtió en el partido dominante del país. Esas elecciones, de cierta forma, extinguieron el tradicional sistema de partidos: mientras en el pasado ADN, MIR y MNR concentraban cerca de 60\% de los votos, en 2005 solo el MNR tuvo alguna representación, con 6,47\% de los votos. En ese mismo año la NFR y el MIP desaparecieron de la escena parlamentar y fueron sustituidos por nuevas fuerzas de oposición al MAS: el movimiento

${ }_{15}$ Como el ex-presidente Jorge Quiroga da ADN en Podemos, partido que llega a aglutinar en su seno a diversas organizaciones políticas que en su mayoría responden a liderazgos regionales. 
Poder Democrático Social (PODEMOS) ${ }^{16}$, la Unidad Nacional (UN) ${ }^{17}$ y el único sobreviviente de los partidos tradicionales, el MNR. El PODEMOS obtuvo 28,69\% de los votos en las elecciones generales; la UN cerca de $8 \%$ y el MNR, 7\%. O sea, solo el MAS y el PODEMOS tenían presencia nacional. Sin embargo, a pesar de el PODEMOS haber sido un fenómeno electoral en aquel momento, no consiguió llegar a las elecciones de 2009 (Carraffa, 2007; Mayorga, F. 2008; Álvarez, 2011). Así, el nuevo sistema partidario boliviano estuvo marcado por la polarización, con el MAS a la frente de una gama fragmentada de políticos tradicionales y líderes regionales. Esa reconstrucción histórica es importante para que entendamos el escenario a partir del cual la izquierda llega al poder en Bolivia. O sea, en un escenario volátil, pero no constituyéndose como un cuerpo orgánico.

Aunque existían conflictos entre el gobierno y la sociedad civil y los movimientos sociales, el liderazgo del MAS fue reforzado en las elecciones de 2009, frente a una oposición dispersa y sin organización. El MSM ${ }^{18}$ consiguió resultados expresivos, pero restrictos al nivel municipal y entre algunos sectores indígenas. La mayor expresión de la oposición vino del Plan Progreso para BoliviaConvergencia Nacional (PPB-CN), coalición de derecha y centroderecha entre los partidos NFR, $\mathrm{MNR}, \mathrm{PPB}^{19}$ y los pequeños partidos $\mathrm{APB}^{20}$ y $\mathrm{PP}^{21}$. El PPB-CN se constituyó en 2009 para concurrir a las elecciones presidenciales, obteniendo $27 \%$ de los votos en las elecciones generales. Sin embargo, no sobrevivió a un segundo ciclo electoral (Centellas, 2015a). En el nivel nacional, el sistema de partidos en 2009 estaba representado por cuatro principales fuerzas: MAS, MSM, PPB-CN y UN. La oposición en las autonomías regionales produjo una dispersión de votos y una fragmentación que, de cierta forma, favorecieron el gobierno (Nunes, 2015).

En 2013 la oposición partidaria al MAS aun se encontraba dispersa e ideológicamente frágil. La mayor fuerza de oposición estaba concentrada en el Frente Amplio, aglutinando varios sectores mayoritariamente de izquierda cuyo liderazgo era ejercido por la UN. Incluía también, en sus liderazgos, exdiputados del MAS y exdirigentes de la CONAMAQ ${ }^{22}$. El MSM siguió también como fuerza opositora de izquierda al MAS, con su sesgo intelectual y una fuerte influencia en La Paz, mayor municipio del país. Sin embargo, tenía una proyección nacional limitada. En 2013 fue también creado el Partido de los Trabajadores de Bolivia (PT) que objetivó convertirse en el brazo político de la $\mathrm{COB}$, pero la aproximación entre la cúpula del sindicato y el gobierno lo puso en la sombra del MAS (Mendoza-Botelho, 2014). De otro lado, en la oposición a la derecha se encontraba la Convergencia Nacional (PPB-CN), un remaneciente del PODEMOS que, aunque mantuviese varios diputados, no tenía un liderazgo claro. Próximo a la PPB-CN se encontraba el Movimiento Social

\footnotetext{
${ }^{16}$ Partido de derecha fundado en 2005 por exdirigentes de la ADN. En 2008 el PODEMOS fue cuestionado por la Corte Electoral acerca del registro de sus militantes y de la necesidad de nueva tramitación de su inscripción. Se sumó a ese el hecho de perder varios liderazgos. En 2009 el partido fue disuelto.

${ }^{17}$ A UN, partido de centroderecha, fue fundada en 2003 a partir de una disidencia del MIR.

${ }^{18}$ Movimiento sin Miedo, partido de centroizquierda creado en 1999 y dirigido por el abogado defensor de los derechos humanos, Juan del Granado. Se inició con la elección por primera vez en 1999 de Granado como alcalde de La Paz, quien fue reelecto en noviembre de 2004 para un nuevo mandato de 5 años. Tenía una alianza con el MAS, que se rompió en 2010, quedando el MAS y el MSM como rivales. Perdió su personalidad jurídica en 2014, cuando no alcanzó el 3\% de los votos en las elecciones presidenciales.

${ }^{19}$ Plan Progreso para Bolivia.

${ }^{20}$ Autonomía para Bolivia, creado en 1999, de centroderecha.

${ }^{21}$ Partido Popular.

${ }^{22}$ Consejo Nacional de Ayllus y Markas Qollasuyo (CONAMAQ), formado en 1997 por el movimiento katarista, con la bandera de reconstitución de los territorios ancestrales devastados por la colonización.
} 


\section{Demócrata (MSD).}

En las elecciones presidenciales de 2014 competieron el MAS, la UD (Concertación Unidad Demócrata), el MSM, el PDC ${ }^{23}$ y el PVB $^{24}$. El MAS venció con $61 \%$ de los votos, con Doria Medina de la UD en el segundo lugar $(24,4 \%)$, en una distancia mayor de la que preveían las encuestas electorales. Los resultados de esas elecciones sugieren que el sistema de partidos boliviano fue realineado (Gráficos 1-6). A pesar de la expresiva pérdida, la oposición tuvo logros en términos de su viabilidad a largo plazo. La UD, el único partido que se ha mantenido en las tres últimas elecciones con relativo éxito en la formación de alianzas con organizaciones políticas en los niveles local y regional y capacidad de reformularse en ese proceso, puede ser colocado ahora como el mayor contrapeso al MAS. Sin embargo, las elecciones de 2014 mostraron que el MAS consolidó su posición como partido hegemónico en Bolivia, consiguiendo la mayoría de los escaños en el parlamento: 67,6\% en la Cámara de Diputados y 69,4\% en el Senado (Centellas, 2015b). En las elecciones subnacionales de 2015 el MAS venció en seis Departamentos.

El análisis de las elecciones presidenciales en Bolivia a partir de 1985 nos muestra que el sistema partidario del país tuvo su formato alterado, con una drástica disminución de la presencia de los partidos tradicionales en el escenario político (ADN, MNR y MIR) y el surgimiento de nuevos partidos. Esa alteración puede ser analizada por su volatilidad, o sea, la rotación entre los partidos entre una y otra elección, lo que nos permite también hablar mínimamente sobre los vínculos de los partidos con la sociedad. Si el electorado no valoriza positivamente la acción del gobierno o los candidatos del partido, ese partido o gobierno puede no alcanzar la cantidad de votos para reelegirse y consolidarse. A su vez, cuanto menos oscilante y más baja la volatilidad, más institucionalizado es el sistema partidario. Lo datos para Bolivia entre 1989 y 2009 muestran grande variación en ese índice y nos sugieren una baja vinculación entre partidos y electores, elemento característico de sistemas partidarios poco institucionalizados (Gráfico 7). Sin embargo, como la volatilidad electoral tiene un fuerte elemento de temporalidad, el análisis de vínculos fuertes o frágiles entre el partido y el electorado debe tomar en cuenta una mayor cantidad de ciclos electorales.

\footnotetext{
${ }^{23}$ Partido Demócrata Cristiano, fundado en 1954 (segundo partido más antiguo del país, después del MNR). No presentaba candidato propio desde $1985 \mathrm{y}$, durante su existencia estuvo apoyando los partidos en la democracia pactada. Es un partido de centro, de oposición al MAS.

${ }^{24}$ Partido Verde Boliviano, fundado en 2007. El PVB construyó una alianza entre CONAMAQ, el Colectivo Manifiesto de la Ciudad de Cochabamba, la agrupación política del TIPNIS y la Confederación de Pueblos Indígenas de Bolivia para concurrir a las elecciones de 2014 de forma independiente del MAS y de otros partidos.
} 


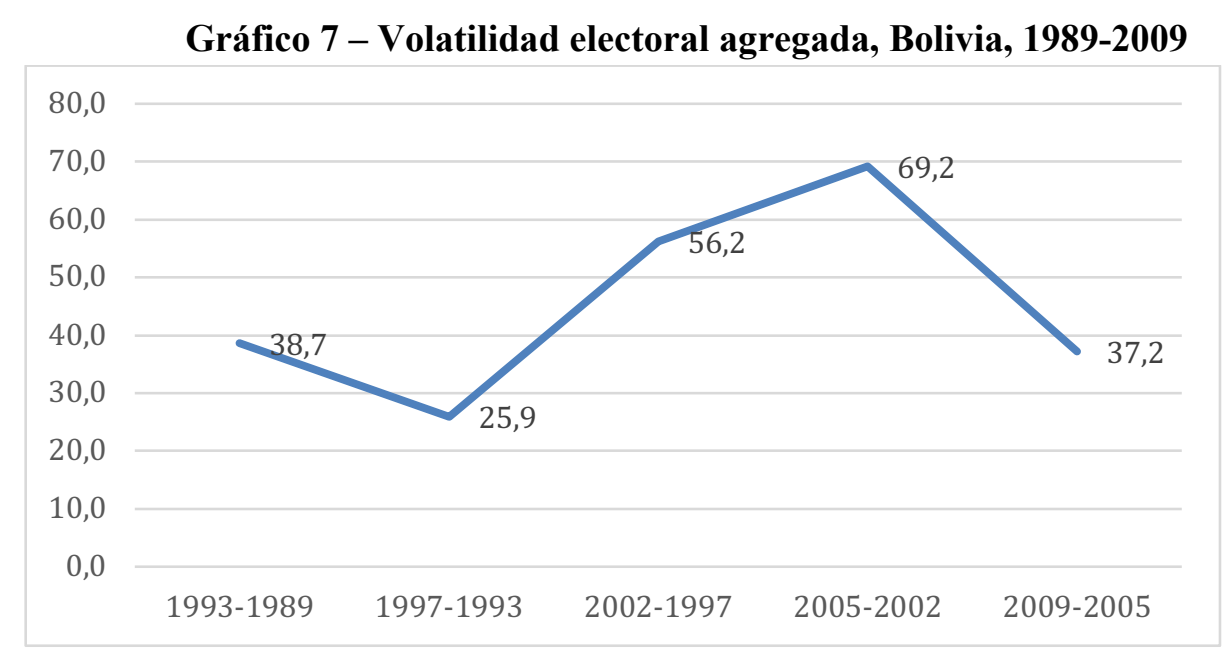

Fuente: Adaptado de Mendieta (2010).

Otro elemento tomado para el análisis de la institucionalización del sistema partidario es su fragmentación, relacionada al número y la fuerza de los partidos, y que afecta las probabilidades del partido en el gobierno obtener apoyo para la aprobación de políticas. Un escenario ideal de gobernabilidad sería de baja fragmentación, o sea, un bajo número de partidos, y de baja distancia ideológica entre ellos. Cuando las dos dimensiones configuran un escenario de alta fragmentación y de alta polarización, el sistema político se vuelve menos gobernable, con dificultades para la formación de coaliciones y predisposición a bloqueos entre el ejecutivo y el legislativo.

En 2004 el sistema partidario boliviano presentaba una alta fragmentación - más de cinco partidos en el parlamento -, y una polarización media entre 1,11 y $3,10^{25}$. Después de las elecciones de 2014 el parlamento boliviano pasó a ser compuesto por cuatro partidos: MAS (izquierda), PDC (a la derecha), MDS (centroderecha) y UN (centroderecha). MDS y UN formaron la coalición UD (a la derecha). Hubo una reducción en la fragmentación de ese sistema, que pasó de un número efectivo de 4,98 partidos en 2004 a 2,07 en 2009 (Gráfico 8).

\section{Gráfico 8 - Número efectivo de partidos electoral y parlamentar en Bolivia (NEPe e NEPp), 1985-2009}

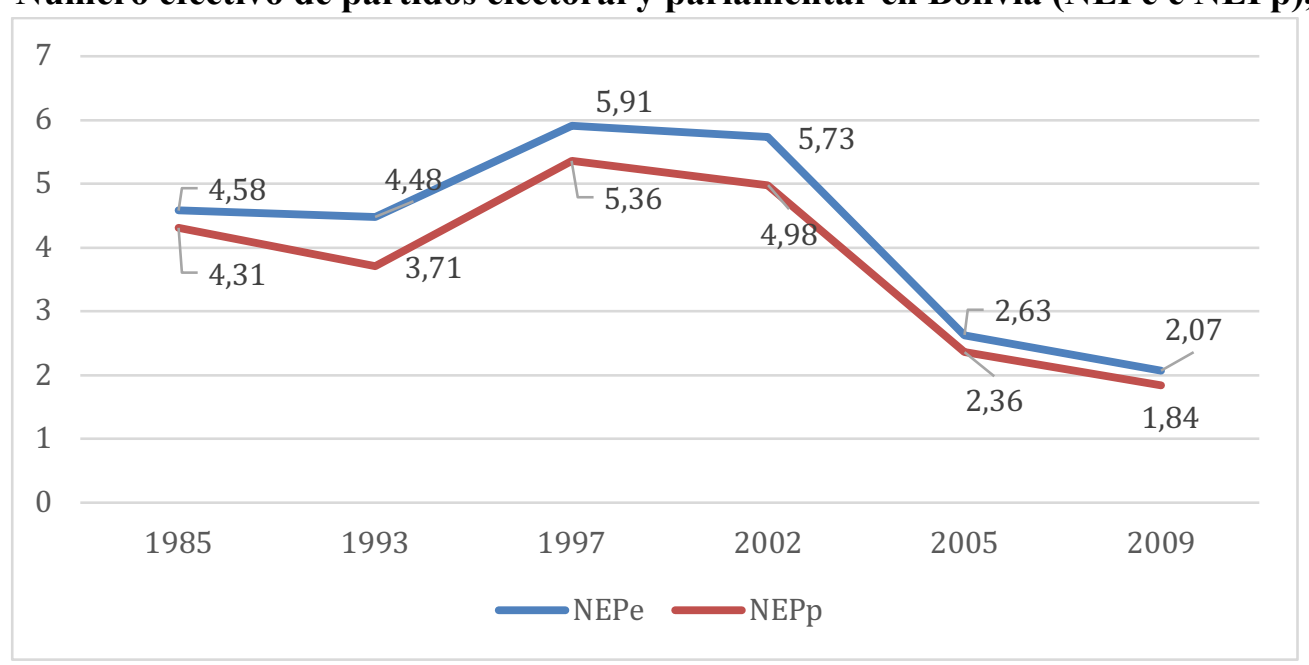

Fuente: Mendieta (2010).

\footnotetext{
25 En la escala: extrema izquierda (1); extrema derecha (10).
} 
En cuanto a la polarización, los datos presentados para el período 1994-2011 muestran una diferencia de 2,14 puntos (en una escala de 0 a 10) entre la posición ideológica del presidente y del parlamento (Alcántara Saéz, 2014). Eso caracterizaría un escenario de gobernabilidad neutra, específicamente en la relación ejecutivo-legislativo: o sea, entre una situación de distancia ideológica entre el presidente y el congreso y ambos en minoría, y otra, de una distancia ideológica reducida y un gobierno con mayoría parlamentar. Bolivia podría ser clasificada entre los países de Latinoamérica con media polarización y media fragmentación del sistema partidario (Alcántara Saéz, 2004, 2014).

Destacamos que situaciones de alta gobernabilidad - baja fragmentación del sistema, mayoría parlamentar y una pequeña distancia ideológica -, confieren mayores poderes legislativos al presidente y tendrían a aumentar la instabilidad del sistema político, dados los incentivos para un gobierno unilateral. En ese argumento, el presidencialismo sería más estable en sistemas en los cuales el presidente depende más de los partidos y, para tanto, sería necesario un sistema partidario institucionalizado. Aun en el argumento, la competencia partidaria criaría condiciones para un mayor equilibrio entre los poderes (Shugart y Mainwaring, 1997; Cunha, 2014). Así, considerando los datos que muestran la disminución de la polarización ideológica en Bolivia y la fragmentación del sistema partidario, y una mayoría parlamentar en el segundo y tercero mandatos del MAS, Bolivia se aproximaría de un modelo favorable a la gobernabilidad, en el cual los poderes legislativos del presidente están incrementados.

\section{El espacio de acción del MAS en el gobierno: el parlamento, la oposición y los movimientos sociales}

En el primer mandato (2005-2009) del MAS la oposición tuvo mayoría en el Senado y en seis de los nueve departamentos. En el Senado, el MAS buscó negociar el apoyo de los partidos más al centro como MNR y UN. La misma acción emprendió en los trabajos de la Asamblea Constituyente.

Algunos análisis sostienen que el MAS, en ese mandato, tendría ignorado la oposición y sus demandas. Sin embargo, ese argumento se debe más al hecho de que la oposición era minoritaria en la Cámara y también en la Asamblea Constituyente, y fragmentada en todas las esferas, lo que favorecía la negociación separadamente con partes de ella. La fragmentación también se repetía en los Departamentos. A pesar de la mayoría de oposición, generalmente esos gobiernos no estaban pactados con los parlamentares, imposibilitando una acción conjunta articulada en la dirección de fines específicos (Reis, 2013).

En el primer mandato, además del control sobre el Senado y sobre los gobiernos departamentales de la media luna ${ }^{26}$, la oposición tuvo una postura defensiva respecto a los proyectos del gobierno y mantuvo como única agenda propositiva la descentralización administrativa con la adopción de las autonomías departamentales. La Asamblea Constituyente fue el escenario de las mayores confrontaciones entre el gobierno, la oposición y los movimientos sociales. Lo que quedó evidente fue una nueva correlación política de poder: primero, entre el gobierno y la oposición en los partidos tradicionales; segundo, entre los bloques indígenas y campesinos, dentro de los movimientos sociales. En el primer caso, el conflicto quedó aparente en los bloqueos al proceso constituyente por

\footnotetext{
26 Departamentos de Tarija Santa Cruz, Beni y Pando.
} 
parte del interés del agronegocio, de los gobernadores y de los comités cívicos regionales, con demandas por autonomía que encubrían la principal cuestión defendida por ellos: el control de los recursos naturales no renovables en el nivel departamental. En el segundo, la existencia de proyectos y propuestas políticas divergentes se reveló en la dinámica interna a los movimientos sociales y especialmente en el Pacto de Unidad ${ }^{27}$. Las organizaciones indígenas demandaban mayores derechos sobre sus territorios y los recursos naturales, así como el deseo de representación directa en las instituciones gubernamentales. O sea, focalizaron en la idea de autogobierno. Los campesinos, por su vez, optaron por la defensa de la reforma en el sistema de gobierno y un proyecto alternativo (Radhuber, 2015). Esa disputa se refleja internamente en el MAS.

Quedó clara, por lo tanto, la polarización entre los partidarios del MAS y la oposición, entre grupos indígenas y campesinos del movimiento social, y entre aquellos que defendían la autonomía departamental. El MAS, para dirimir los conflictos y conseguir aprobar la convocación del referendo de aprobación del texto constitucional, negoció el tratamiento de su contenido con la oposición. Se formó una comisión parlamentar y una subcomisión técnica con las funciones de coordinación del diálogo sobre los puntos conflictivos del texto. Las deliberaciones fueron concluidas en octubre de 2008, con la modificación de cerca de 100 artículos. La consulta por referendo y la promulgación de la nueva Constitución ocurrieron en enero de 2009.

La solución de los conflictos pasó también por la convocación del referendo revocatorio, con el objetivo de definir la permanencia de los gobernadores de los Departamentos y del presidente y vicepresidente. Se trató de una estrategia del gobierno, a la cual la oposición adhirió creyendo conseguir evitar la aprobación de la nueva Constitución (Zegada et al., 2011). Sin embargo, los resultados del referendo revocatorio fueron favorables al gobierno, ampliando su legitimidad (el "Sí" para Evo Morales alcanzó 67,4\% de los votos válidos; cuatro gobernadores de la oposición y dos del gobierno fueron ratificados; y tres gobernadores de la oposición tuvieron su mandato revocado). En esa etapa el gobierno controló la agenda política y la oposición (Zegada et al., 2011; Cunha Filho, 2014). El MAS se consolidó como el partido dominante en el país, cercado por una multiplicidad de fuerzas de oposición sin capacidad de contener su avance. La solución de los conflictos, favorable al gobierno, puede explicarse por factores como la fragmentación sea de la oposición, sea entre los movimientos sociales o en los Departamentos, y por el desgaste principalmente de esos últimos en consecuencia de las acciones violentas que emprendieron.

El primer mandato del MAS fue caracterizado, por lo tanto, por la existencia de limites y constreñimientos institucionales al poder decisorio del presidente. Sin embargo, se observa que, en ese escenario político-institucional, el MAS fue el actor mejor posicionado, sea por el apoyo popular que no solo se mantuvo, sino que también fue incrementado, sea por haber conseguido el consenso sobre el texto constitucional con los actores de la oposición en el parlamento.

Con la nueva Constitución de 2009 la elección presidencial en Bolivia pasó a ser directa, con dos variantes en el caso de la ausencia de un vencedor por mayoría absoluta. Primero, queda electo aquel que obtiene votación superior a $40 \%$ y una diferencia de 10 puntos respecto al segundo candidato más votado. Caso eso no ocurra, la elección se define mediante segundo turno en las urnas entre los dos candidatos más votados. O sea, la legitimidad del presidente es privilegiada y se contorna

\footnotetext{
${ }^{27}$ Pacto conformado en 2004 con intento de unificar los distintos actores indígena-campesinos, en una coyuntura de fuertes disputas políticas.
} 
el riesgo de una legitimidad dual con el parlamento caso la autoridad carezca de respaldo mayoritario en el Poder Legislativo. Se modificó la regla de distribución de sillas en el Senado y se reconocieron circunscripciones indígenas uninominales en la Cámara de Diputados $\mathrm{y}$, con ello, en el ámbito parlamentar, la cantidad de senadores fue incrementada de 27 para 36. Para ampliar la democracia participativa y directa fueron formalizados los referendos y la revocatoria del mandato. La nueva Constitución también implementó el régimen de autonomías en el nivel subnacional, con un proceso de descentralización política por medio de la conformación de gobiernos departamentales, regionales, municipales e indígenas, esquema que favoreció la generación de subsistemas políticos y propició el enriquecimiento de la dinámica política democrática (Zegada, 2010; Mayorga, F. 2012). Sin embargo, el gobierno nunca consideró legítima la demanda por autonomía y, frustrándola, la Constitución de 2009 mantiene en el gobierno central el control exclusivo sobre los recursos naturales, distribución de tierras y política económica, mientras cede poderes legislativos y responsabilidades administrativas menores para los gobiernos subnacionales (Rice, 2011).

\section{El escenario de las relaciones entre los niveles de gobierno - la cuestión de las autonomías}

Por fin, para entender mejor los cambios recientes y la dinámica del escenario político boliviano nos interesa discutir una innovación del texto constitucional: la substitución del paradigma geopolítico del Estado Unitario por un nuevo Estado Plurinacional. Ese cambio instituyó las autonomías indígena, municipal, departamental y regional. El Estado plurinacional presupone la convivencia de autonomías administrativas y culturales. O sea, si la autonomía es de solo un tipo, el Estado no es plurinacional. A partir de esa lógica fue necesario también admitir la posibilidad de la existencia de autonomías indígenas originarias extraterritoriales, principalmente cuando se consideró que los territorios pueden tener una población compuesta (Santos, 2007). En parte, esos cambios representan una profundización de la agenda de reformas implementadas durante los años 1990, que promovieron algunas importantes innovaciones institucionales, como la municipalización por medio de la institución de elecciones directas y de la autonomía financiera de las municipalidades y la creación de los territorios de origen, que pasaron a poder ser titulados a los pueblos indígenas, con el objetivo de conferir a ellos la garantía del control de sus territorios ancestrales (Fontana, 2012, p. 13).

La búsqueda de autonomía - bien como la defensa de reformas para la elección de gobernadores, de referendos para aprobación de las autonomías, y de la creación de estatutos autonómicos -, venían desde la década de 90, en función de un gobierno central excesivamente centralizador. Había también una cuestión económica: los Departamentos consideraban que la distribución de los recursos entre ellos era desigual, algunos por recibir menos recursos, otros por tener de redistribuir los suyos. Seis de ellos no contaban con los altos ingresos que disponían La Paz, Cochabamba y Santa Cruz, que acababan por ser redistribuidos por medio del gobierno central. O sea, os Departamentos buscaban la libertad para manejarlos y administrar no solo lo que venía del Tesoro General de la Nación (TGN), sino que también sus propios recursos, por ejemplo, abriendo espacios a nuevos comercios internacionales no permitidos entonces por el gobierno central. Por otro lado, los gobiernos locales y departamentales cuestionaban la baja presencia del Estado en el territorio nacional, percibida por la falta de inversiones en las diversas regiones. Se sumaba a eso la queja acerca de los escasos canales de participación democrática. 
En el intento de alcanzar la demanda por autonomía, entre 1982 y 1993 fueron formulados 20 proyectos de ley de descentralización. En 1994 la reforma constitucional creó nuevas estructuras administrativas, con la delegación de tareas y decisiones al nivel departamental y la creación de gobiernos municipales con funciones normativas, ejecutivas, administrativas y técnicas. Con eso fueron transferidas competencias del nivel central del Estado a los 311 municipios, cuyas administraciones fueron designadas como gobiernos locales autónomos. La autonomía significó, por un lado, la elección del gobierno municipal y, por otro, el derecho de ese gobierno recoger algunos impuestos y planear la administración, especialmente en las áreas sociales (Botero, 2015; StröbeleGregor, 1999). Aun en ese año el presidente Sánchez de Lozada (1993-1997) promulgó la Ley de Participación Popular que promovía la descentralización política para el municipio, esta complementada en 1995 por la Ley de Descentralización Administrativa, que regía la descentralización administrativa hasta el Departamento. Entre otros, la Ley de Participación Popular descentralizó a los municipios $20 \%$ de la receta fiscal nacional, cuya asignación debería ser definida en los respectivos estatutos autonómicos municipales, y las fronteras de los municipios fueron expandidas para incluir distritos y áreas rurales, siendo creados nuevos municipios, totalizando 328. Esas medidas representaron un profundo cambio institucional, ya que antes el gobierno local no existía en la mayor parte de Bolivia (Faguet, 2013).

La descentralización llevó a profundos cambios en el flujo de recursos en Bolivia. Antes de la reforma, solo $14 \%$ de los recursos del gobierno central eran compartidos con la mayoría de los municipios, mientras tres ciudades del país recibían $86 \%$ de esos recursos. Tras la descentralización esa proporción fue revertida: $73 \%$ de los recursos eran distribuidos con la mayor parte de los municipios y $27 \%$ para las tres principales ciudades del país. El criterio per cápita resultó en un cambio drástico del flujo de los recursos de los centros más ricos para los distritos rurales más pobres. Con respecto a la asignación de los recursos, la inversión total en educación aumentó 547\% (considerando 1991-1993 y 1994-1996); en salud, 43\%, y en abastecimiento de agua y saneamiento, 133\% (Faguet, 2013).

La descentralización, por lo tanto, parece haber reorientado la inversión pública, dando evidencias de las consecuencias de todo ese cambio institucional. Sin embargo, los analices de la Ley de Participación Popular varían cuanto a la evaluación de sus efectos. Algunos apuntan para los significativos cambios que trajo, específicamente respecto al incremento de la participación popular en los gobiernos locales. Otros apuntan para el hecho de que promovió la fragmentación social, facilitó la corrupción local y priorizó las inversiones sociales en salud y en educación, en detrimento de las inversiones productivas necesarias para superar la pobreza. Otros, aun, evalúan que existían problemas relacionados con la capacidad local e la insuficiencia de recursos en contextos de grandes necesidades, aunque reconozcan que hubo un incremento en la democracia y en el empoderamiento de los ciudadanos bolivianos más pobres (Cabrera, 2011; Faguet, 2013, 2009).

Más tarde, la Constitución de 2009 y la posterior Ley Marco de Autonomías y Descentralización de 2010 definieron la descentralización política por medio de las autonomías territoriales. En ese marco, cambia substancialmente el carácter de las autonomías, dado que su diseño involucra niveles de administración con base territorial y la redistribución de poder en las dimensiones política, económica y simbólica (Zegada et al., 2011). Como resaltamos, la demanda por las autonomías en Bolivia históricamente fue planteada por los liderazgos regionales $\mathrm{y}$, específicamente en el gobierno del MAS, por los grupos de oposición en los Departamentos. De toda 
forma, en el proceso constituyente el gobierno asumió esa demanda, no necesariamente abrazando los mismos intereses de aquellos que la propusieron.

La Ley Marco de Autonomía y Descentralización revocó la Ley de Participación Popular de 1994 y la Ley de Descentralización Administrativa de 1995, y regula la organización territorial del país, integrando el concepto de autonomía al régimen de descentralización municipal y departamental. Se definieran cuatro niveles de autonomía: departamental, regional, municipal e indígena. Mientras los tres primeros representan una clara jerarquía respecto a la extensión territorial y al nivel de gobierno, el cuarto es cualitativamente diferente en términos de organización social y política. La autonomía indígena permite que las comunidades, respectando los derechos y garantías constitucionales, apliquen sus principios y formas de autogobierno, defiendan su cultura y organicen su economía. Territorialmente, el país pasa a ser organizado en los nueve Departamentos, que se dividen en 112 provincias y en 339 municipios y territorios indígena-originario-campesinos.

El proceso de implementación de las autonomías tiene un carácter vertical, por lo cual el gobierno central cede algunas competencias a los niveles subnacionales. Son definidos por los poderes y deberes de cada gobierno respecto a los recursos y, específicamente, en relación a la salud, vivienda, abastecimiento de agua y saneamiento, educación, transporte, entre otros. La autonomía abarca la elección directa de los representantes, la administración de los recursos económicos, el ejercicio de las facultades legislativas locales y el uso de poderes coercitivos. Alcanzarla demanda un procedimiento que incluye la elaboración y aprobación de su estatuto por la Asamblea departamental o municipal, la tramitación de este en el Tribunal Constitucional Plurinacional y su sumisión a un referendo ratificatorio. En el caso de las autonomías regionales es necesaria la elaboración de un plano regional de desarrollo consonante con el plan nacional.

Las evaluaciones de la Ley Marco de Autonomías y Descentralización deben ser cuidadosas, dado el corto tiempo de su implantación. Sin embargo, algunas aproximaciones entienden que la implementación formal de las autonomías, en realidad, las disminuye y refuerza la centralización. Esos analices también resaltan las tendencias centralizadoras del gobierno del MAS, que trasparecieron en varios artículos de esa ley y de la Constitución de 2009, contradiciendo y minando la real autonomía que propagaron (Faguet, 2013). Uno de los puntos de críticas se refiere a los desequilibrios fiscales horizontales que pueden originar, considerando la tendencia de disminución de los recursos propios de los gobiernos subnacionales frente al aumento de sus atribuciones. Eso los dejaría dependientes de los recursos y prioridades del gobierno central. Para Faguet (2013) cuestiones de esa naturaleza reflejan la visión de que la autonomía es más benéfica a los gobiernos subnacionales en el ámbito político - en el cual puede promover accountability -, que en el ámbito fiscal, que puede llevar a la insustentabilidad de los proyectos locales. O sea, el régimen de autonomías previsto en la legislación pretende que los gobiernos sean responsables por sus gobernados, promoviendo canales electorales y no-electorales de participación, mientras deja mucha discrecionalidad para el nivel central del gobierno en términos de la asignación y de las reglas de transferencia físcal.

En suma, la virtud de la Ley Marco de Autonomías y Descentralización está en la distribución de las competencias, en búsqueda de un modelo coherente de autonomías. Sin embargo, mantiene cuestiones cruciales bajo la tutela del gobierno central, dificultando el ejercicio de las competencias allí determinadas. En ese punto, se materializó la hegemonía del MAS en el proceso decisorio, resguardando cuestiones con las cuales divergía en respecto a las demandas, en esa cuestión particular. 
¿Y cómo ese escenario estaba ligado a lo que ocurría en el sistema partidario y político? Las elecciones presidenciales y legislativas de 2009 y las elecciones departamentales y municipales de 2010 modificaron el escenario de la correlación de fuerzas. El MAS obtuvo mayoría de las sillas parlamentares y pasó a controlar ambas las casas. Seis de los nueve gobernadores electos pasaron a ser gubernistas, a lo que se sumó la mayoría de las victorias en el nivel municipal en 2010 (65\% de los municipios), como mostrado en el Gráfico 9 (Mayorga, F. 2012; Rice, 2011). La conquista de la mayoría de los gobiernos municipales es un factor importante, pues en la medida que las élites regionales de la media luna fueron perdiendo el control del poder político, esas elecciones se van volviendo más disputadas. La oposición busca ganar espacio en los niveles subnacionales, dado que en el escenario nacional está derrotada. Aun con esa disputa la presencia del MAS en los municipios aumentó 67,6\% en 2015, respecto a las elecciones de 2010. En las capitales de los Departamentos la oposición consiguió mayoría en 2010, venciendo en siete de ellas (Rice, 2011). En 2015 el MAS retomó la mayoría de esas capitales, venciendo en seis de ellas.

\section{Gráfico 9 - Proporción de municipios gobernados por el MAS, por Departamento, alcanzada por los procesos electorales de 2010 e 2015}

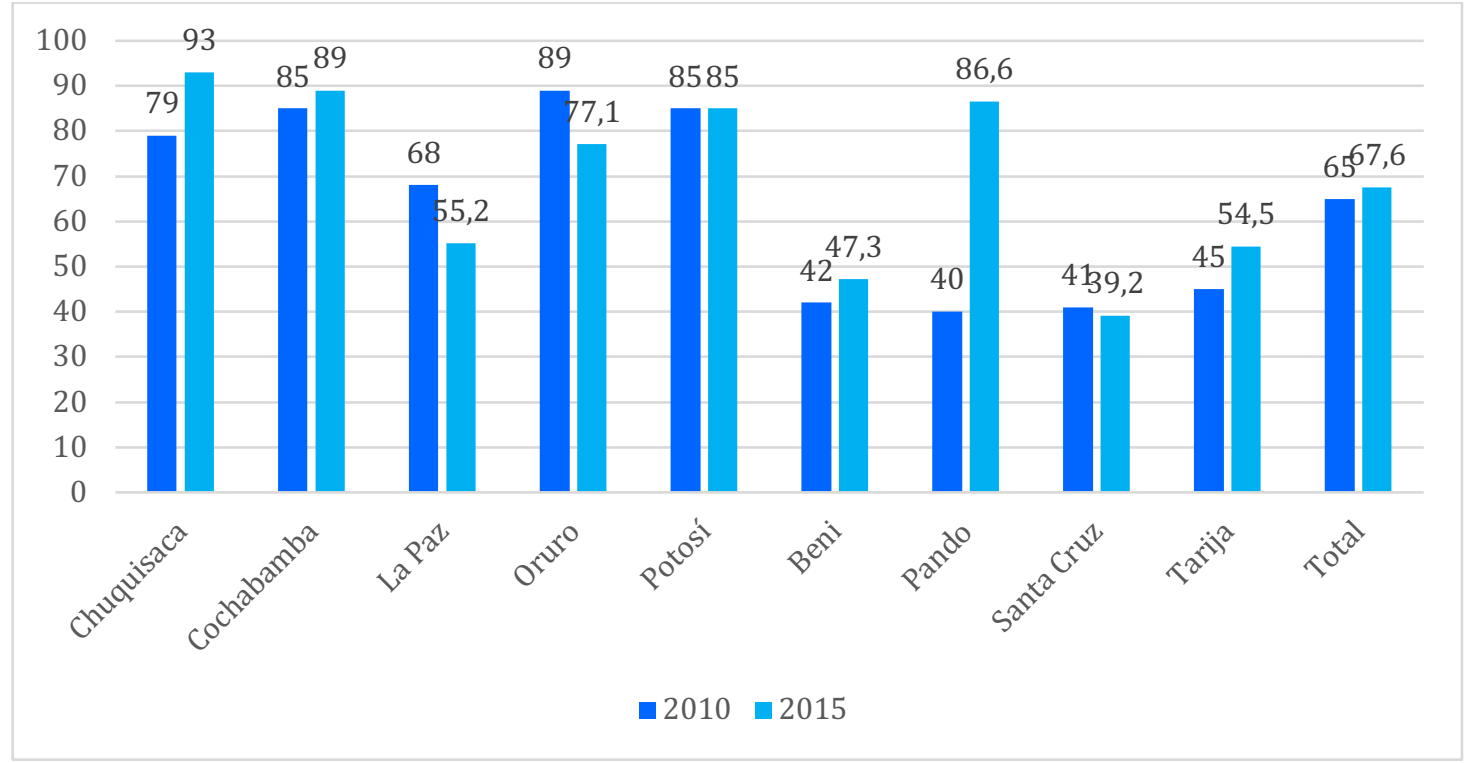

Fuente: Elaboración propia a partir de datos del Órgano Electoral de Bolivia.

Así, a partir del segundo mandato del MAS se tiene un gobierno de mayoría, con el sistema partidario caracterizado por un partido hegemónico, donde las fuerzas de oposición tienen poca relevancia, en que pese el logro alcanzado en las capitales. Tenemos en ese periodo, por lo tanto, un presidencialismo sostenido por una fuerza política que domina el parlamento y se impone frente a una oposición aun fragmentada. O sea, en ese momento del país, en el cual un nuevo orden estatal estaba en proceso de construcción por medio de la aprobación de leyes infraconstitucionales, la definición de las reglas del juego dependía de la voluntad y capacidad legislativa de un solo actor político - el partido del gobierno -, cuyo accionar dependía de las decisiones del presidente (Mayorga, F. 2012). Para Fernando Mayorga (2012), el modelo presidencialista de coalición en los gobiernos anteriores (entre 1985 y 2002) tenía una figura análoga al de la gestión del MAS en ese momento, dado que el presidente era el jefe del gobierno, de la coalición y del partido cabeza de la coalición. El autor considera, sin embargo, que esa centralización del poder en el presidente era más amena, visto 
que las interacciones partidarias dentro de la coalición, en los gobiernos neoliberales, proporcionaban matices a las decisiones. Allí existían diferentes posturas e intereses entre los partidos de las coaliciones, aunque existiese un proyecto dominante pautado en la articulación entre la democracia y el neoliberalismo económico.

\section{Consideraciones finales}

El análisis estuvo focalizado en los cambios institucionales recientes del escenario boliviano. Al rastrear los principales procesos en curso, es posible destacar dimensiones que conforman cambio institucional en Bolivia: 1) el desmantelamiento de los partidos tradicionales; 2) la volatilidad del sistema partidario; 3) el rediseño de las reglas del juego, o sea, cambios en la arena constitutiva lowiana, representados no solo por la Constitución de 2009, sino que por la Ley Marco de Autonomías y Descentralización de 2010; 4) por fin, el surgimiento y la consolidación del MAS como fuerza política capaz de contraponer las fuerzas tradicionales. Pero, hubo también la reconfiguración del Estado de unitario para plurinacional, estableciendo nuevos actores sociales y políticos con poder de entrar en la arena política, y también de la relación entre los Departamentos, los municipios y el gobierno central. Esos cambios proporcionan condiciones para la profundización de la democracia, aproximando las demandas y necesidades de los ciudadanos, permitiendo la creación de espacios que abarquen la diversidad sociocultural del país, y por dar relevancia a la autonomía indígena.

Si hasta fines de la década de 90 la izquierda no había se constituido como presencia de peso en la escena política boliviana, el MAS hoy representa su principal actor político. El análisis muestra que el surgimiento y el fortalecimiento del MAS se dio en concomitancia al desmantelamiento de los partidos tradicionales de la escena política boliviana post abertura democrática. Las fuerzas partidarias tradicionales de la década de 90 no se sostuvieron frente al apoyo electoral creciente y consistentemente levantado por el MAS. Paralelo a esto, se observa la volatilidad de los partidos, mostrando la instabilidad del sistema y la dinámica interna de ese momento. Dentro de ese escenario, argumentamos que la entrada del MAS es uno de los elementos que reconfiguró la escena política de Bolivia, desestabilizando los demás actores. El rastreo de los acontecimientos nos permitió inferir eso, principalmente por los cambios legales protagonizados por el MAS, algunos de ellos en oposición no solo a los demás partidos, como a la mayoría de los Departamentos. Aunque varios de esos movimientos puedan ser rastreados desde gobiernos anteriores, fue solamente a partir del protagonismo del MAS que tales cambios fueron posibles.

\section{Referências}

ALCÁNTARA SAÉZ, Manuel. Elecciones en América Latina: un análisis comparado. Revista Latinoamericana de Política Comparada, v. 8, p. 11-42, 2014.

. Partidos políticos en América Latina: precisiones conceptuales, estado actual y retos futuros. Documentos CIDOB. Serie América Latina, n. 3, 2004.

ÁLVAREZ, Luis Daniel. Los partidos políticos en Bolivia: la volatilidad de un país expresada en sus organizaciones políticas. Argos, v. 28, n. 54, p. 107-126, 2011. 
ANRIA, Santiago. Bolivia's MAS: Between Party and Movement. In: CAMERON, Maxwell A.; HERSHBERG, Eric (Eds.). Latin America's Left Turns: politics, policies, and trajectories of change. Boulder: Lynne Rienner Publishers, 2010.

BALLIVIÁN, Salvador Romero. El sistema de partidos en Bolivia (1952-2015): del partido hegemónico al partido predominante. In: FREIDENBERG, Flavia (Ed). Los sistemas de partidos en América Latina 1978-2015: Cono Sur y Países Andinos. Ciudad de México: Universidad Nacional Autónoma de México, 2016. Tomo 2.

BOTERO, Daniel Indalecio R. Neoliberales y empresarios en la emergencia de la descentralización en la Bolivia de los 90. Revista de Historia Nacional y Local, v. 7, n. 14, p. 322-350, 2015.

CABRERA, Juan E. La construcción del territorio plurinacional. Bolivia de 1960 a 2010. Territórios, n. 24, p. 13-58, 2011.

CARRAFFA, Carlos C. La gobernabilidad democrática: alcances y límites de los pactos, la relación entre los poderes. 25 años de democracia en Bolivia. Tomo I. Opiniones y Análisis, n. 87, p. 69-95, 2007.

CENTELLAS, Miguel. Cycles of reform: placing Evo Morales's Bolivia in context. Latin American Research Review, v. 50, n. 1, p. 229-241, 2015a. $\overline{97,2015 b .}$

The 2014 presidential and legislative elections in Bolivia. Electoral Studies, n. 37, p. 94-

CUNHA, Lucas. Presidencialismo e mudança a América do Sul: a agenda política dos presidentes identificados com as "esquerdas" e os desafios da governança e da estabilidade democrática. Anais do IX Encontro da ABCP. Brasília, 2014.

CUNHA FILHO, Clayton. El "proceso de cambio" en Bolivia: un balance de ocho años. Tinkazos, v. 37, n. 35, p. 135-153, 2014.

FAGUET, Jean-Paul. Can subnational autonomy strengthen democracy in Bolivia? The Journal of Federalism, v. 44, n. 1, p. 51-81, 2013.

. Governance from below in Bolivia: a theory of local government with two empirical tests. Latin American Politics and Society, v. 51, n. 4, p. 29-68, 2009.

FONTANA, Lorenza B. The "Processo de Cambio" and the Seventh Year Crisis: Towards A Reconfiguration Of The Relationship Between State And Social Movements In Bolivia. Bolivian Studies Journal, v. 19, p. 190-212, 2012.

MADRID, Raul. Bolivia: Origins and policies of the Movimiento al Socialismo. In: LEVITSKY, Steven; ROBERTS, Kenneth (Eds.). The Resurgence of Latin American Left. Baltimore: The Johns Hopkins University Press, 2011.

MAINWARING, Scott; SCULLY, Timothy. Party systems in Latin America. In: MAINWARING, Scott; SCULLY, Timothy. Building democratic institutions: Party systems in Latin America. Palo Alto: Stanford University Press, 1995.

MAINWARING, Scott; TORCAL, Mariano. Party system institutionalization and party system theory after the third wave of democratization. Kellogg Institute for International Studies. Working Paper 319, 2005.

MAÍZ, Ramón. Indianismo e etnonacionalismo na Bolívia. Tensões Mundiais, v. 5, n. 8, p. 11-38, 2009. 
MAYORGA, Fernando. La democracia boliviana: avances y desafíos. In: DARGATZ, Anja; ZUAZO, Moira (Eds.). Democracia en transformación. ¿Qué hay de nuevo en los nuevos Estados andinos? Ecuador: Fundación Freidrich Ebert, 2012.

. El gobierno de Evo Morales: cambio político y transición estatal en Bolivia. In: MURAKAMI, Yusuke (Ed.). Tendencias políticas actuales en los países andinos - CIAS Discussion Paper n. 5. Kioto: Kyoto University, 2008.

MAYORGA, René Antonio. La crisis del sistema de partidos políticos: causas y consecuencias: Caso Bolivia. Cuadernos del Cendes, v. 21, n. 57, p. 83-114, 2004. 35-60, 1994.

Gobernabilidad y reforma política. La experiencia de Bolivia. América Latina Hoy, n. 8, p.

MENDIETA, Javier Gustavo P. Bolivia: elecciones presidenciales y legislativas (1993-2009). Salamanca: Instituto de Iberoamérica/Universidad de Salamanca, 2010.

MENDOZA-BOTELHO, Martín. Bolivia 2013: al calor preelectoral. Revista de Ciencia Política, v. 34, n. 1, p. 37-57, 2014.

NUNES, Edson C C. Bolívia: crise do tradicional sistema de partidos e novas pautas de funcionamento do sistema político. Agenda Política - Revista de Discentes de Ciência Política da UFSCAR, v. 3, n. 1, p. 31-48, 2015.

PRIBBLE, Jennifer. Creating universalistic health policy: the role of policy legacies, electoral competition, and party character. In: PRIBBLE, Jennifer. Welfare and party politics in Latin America. Cambridge: Cambridge University Press, 2013.

RADHUBER, Isabella M. State power and political power balance in Bolivia: an analysis trough laws and finance. Latin American Policy, v. 6, n. 1, p. 89-109, 2015.

REIS, Guilherme S. A social-democracia do MAS boliviano. Revista Sociologia e Política, v. 21, n. 48, p. 67-84, 2013.

RICE, Roberta. Regional autonomy and municipal politics in post-neoliberal Bolivia [Online]. In: Annual Meeting of the American Political Science Association. Washington DC, 2011. Available in: https://ssrn.com/abstract=1901983. Access in: 16 Oct. 2016.

SANTOS, Boaventura S. La reinvención del Estado y el Estado plurinacional. OSAL, año VIII, n. 22, p. 25-34, 2007.

SHUGART, Matthew S; MAINWARING, Scott. Presidentialism and democracy in Latin America: rethinking the terms of the debate. In: SHUGART, Matthew S; MAINWARING, Scott (Eds.). Presidentialism and democracy in Latin America. Cambridge: Cambridge University Press, 1997.

STRÖBELE-GREGOR, Juliana. Ley de Participación Popular y movimiento popular en Bolivia. In: HENGSTENBERG, Peter et al. (Eds.). Sociedad civil en América Latina: representación de intereses y gobernabilidad. Caracas: Nueva Sociedad, 1999.

TORRICO, Mario. Bolivia: nuevo sistema electoral presidencial y coordinación política de los partidos. Perfiles latinoamericanos, v. 22, n. 43, p. 77-102, 2014.

WEYLAND, Kurt. The rise of Latin America's two lefts: insights from rentier state theory. Comparative Politics, v. 41, n. 2, p. 145-164, 2009.

ZEGADA, Maria Teresa. Los nuevos contornos de la izquierda boliviana. Tinkazos, v. 15, n. 31, p. 121-125, 2012. 
. El rol de la oposición política en Bolivia (2006-2009). In: ORELLANA, Alberto García; YAPUR, Fernando García; BALLIVIÁN, Salvador Romero (Eds.). Mutaciones del campo político en Bolivia. Bolivia: PNUD, 2010.

ZEGADA, María Teresa et al. La democracia boliviana y sus (re)significaciones. In: ZEGADA, María Teresa et al (Eds.). La democracia desde los márgenes: transformaciones en el campo político boliviano. Bolivia: Clacso, 2011.

Artigo submetido em: Fevereiro/2019

Artigo aprovado em: Dezembro/2019

Rosiene Freitas (rosie.freitas04@gmail.com) é pesquisadora no Núcleo de Educação em Saúde Coletiva da Faculdade de Medicina, Universidade Federal de Minas Gerais (UFMG). Doutora em Ciência Política pela Universidade Federal de Minas Gerais (UFMG).

Natália Guimarães Duarte Sátyro (nsatyro@gmail.com) é professora associada na Universidade Federal de Minas Gerais (UFMG). Doutora em Ciência Política pelo Instituto Universitário de Pesquisas do Rio de Janeiro (IUPERJ).

\title{
Dos Décadas de Cambios en el Escenario Político y Partidario de Bolivia: el lugar del MAS y de los demás
}

\begin{abstract}
Resumen. El articulo analiza los principales cambios en los sistemas político y partidario de Bolivia en la historia reciente, con foco en el lugar y el papel del MAS (Movimiento al Socialismo), a través de la técnica del rastreo de los procesos (process tracing) que conforman el cambio de ese escenario institucional. Se discute el surgimiento del MAS y cómo él se vuelve actor central en la arena política en las dos últimas décadas. En seguida, son analizados los escenarios político y partidario en los cuales gobierna, y la relación con los diversos actores: parlamento, oposición, movimientos sociales, Departamentos y municipios. Los resultados señalan el desmantelamiento de los partidos tradicionales y un sistema partidario volátil, el rediseño de las reglas del juego y la consolidación del MAS como fuerza política.
\end{abstract}

Palabras-clave: Izquierda; Bolivia; Partido Político; MAS.

\section{Two Decades of Changes in the Bolivian Political and Partisan Arenas: the place of MAS and the other parties}

\begin{abstract}
The article analyzes the main changes in Bolivia's political and party systems in recent times, focusing on the place and role of the MAS (Movimiento al Socialismo), using the technique of process tracing that make up the change in that institutional arena. It discusses the emergence of MAS and how it becomes central actor within the political arena in the last two decades. Next, the political and party scenarios in which it governs are analyzed, as well as the relationship with the various actors: parliament, opposition, social movements, departments and municipalities. The results
\end{abstract}


point to the dismantling of traditional parties and a volatile party system, the redesign of the rules of the game and the consolidation of MAS as a political force.

Keywords: Left; Bolivia; Political Party; MAS. 